\title{
Complications after laparoscopic gastric banding in own material
}

\author{
Hady Razak Hady ${ }^{1}$, Jacek Dadan ${ }^{1}$, Maria Sołdatow ${ }^{1}$, Robert Jerzy Ładny' ${ }^{1}$, Paweł Gołaszewski ${ }^{1}$, Eugeniusz Wróblewski², \\ Andrzej Dąbrowski \\ ${ }_{1}^{1} 1^{\text {st }}$ Department of General and Endocrinological Surgery, Medical University of Bialystok, Poland \\ 2Department of Gastroenterology and Internal Medicine, Medical University of Bialystok, Poland
}

Videosurgery Miniinv 2012; 7 (3): 166-174

DOI: 10.5114/wiitm.2011.27605

\begin{abstract}
Introduction: Complications after bariatric procedures are the most difficult to diagnose among all complications in abdominal surgery. Furthermore, they are extremely difficult to treat conservatively and surgically. Laparoscopic treatment of complications after bariatric procedures requires great skills. Complications after laparoscopic adjustable gastric banding (LAGB) are remarkably diverse.

Aim: Presentation of complications after $L A G B$ in our own material.

Material and methods: From 2005 to 2010, in the 1st Department of General and Endocrine Surgery, in 110 patients adjustable gastric banding was applied. All procedures were conducted laparoscopically. The group consisted of 76 women (69.1\%) and 34 men (30.9\%). The average age of women was $37.7 \pm 13.80$ years old. The average age of men was $38.9 \pm 11.50$ years old. The average body mass was $128.5 \pm 24.35 \mathrm{~kg}$ for women and $125.4 \pm 23.60 \mathrm{~kg}$ for men. The average body mass index (BMI) for women was $44.08 \pm 3.03 \mathrm{~kg} / \mathrm{m}^{2}$ and for men $43.66 \pm 2.90 \mathrm{~kg} / \mathrm{m}^{2}$. The average waist circumference was $113.5 \pm 12.75 \mathrm{~cm}$ in women and for men it was $124.40 \pm 14.8 \mathrm{~cm}$.

Results: In the analysed material, which consisted of 110 patients after LAGB, 36\% developed at least 1 complication. Among early complications, injury of diaphragm, pneumothorax, pleural empyema, gastric perforation and thrombophlebitis were observed. Among late complications, oesophagitis, infections around the port, migration of the gastric band into the gastric lumen, band slippage, vomiting and lack of body mass loss were observed. The most common reasons for the removal of the band were band slippage, its migration to the gastric lumen and extension of the gastric reservoir.

Conclusions: The $L A G B$ is a relatively easy procedure with a short time of performance and short hospitalization. However, it can bring the risk of intraoperative, perioperative and late complications which require surgical intervention. The present research results are comparable to world data. Complications after LAGB were observed the most frequently in the first years of application of the procedure.
\end{abstract}

Key words: obesity, gastric banding, complications.

\section{Introduction}

Obesity is one of the most common issues in modern medicine. Its global scale and the growing number of obese people document the development of the global epidemic. Adiposity is connected with concurrent diseases such as diabetes, arterial hypertension, dyslipidaemia, and diseases of the respiratory, circulatory and osteoarticular system. The relationship between obesity and numerous neoplasms has also been proven. In the face of unsatisfactory conservative means, surgery

Address for correspondence:

Hady Razak Hady MD, $1^{\text {st }}$ Department of General and Endocrinological Surgery, Medical University of Bialystok, 24 A Sklodowskiej-Curie, 15-276 Bialystok, Poland, phone: +48 8574686 72, fax: +48 8574686 20, e-mail: klchirog@umwb.edu.pl 
plays an important part in obesity management. Advancing laparoscopic techniques, which are now a method of choice in bariatric surgery, led to development and increased popularity of bariatric procedures $[1,2]$. Available treatment options include restrictive, malabsorptive or a combination of both. Many factors such as body mass index (BMI), general performance status, age, concurrent diseases, operating room and ward equipment, and also the surgeon's skills and experience influence the decision about the technique [3]. The risk connected with general anaesthesia is especially important in the choice of the technique as the rule "big patient - big risk" is applicable. The surgery should be adjusted so that it guarantees the highest percentage of body weight loss with the minimal surgical risk [4]. Laparoscopic adjustable gastric banding (LAGB) is still very popular among restrictive surgical techniques. At the moment, it is one of the most commonly performed bariatric procedures in the world [5]. The sense of satiety arises fast due to the band creating a small reservoir in the upper stomach despite a decreased amount of food intake. The frequency of gastric banding adjustment depends on the pace of weight loss. The use of an adjustable gastric band should be mainly considered in young patients, who will accept postoperative dietary restrictions and necessary constant cooperation together with medical supervision. One of the contraindications for this method of treatment is unpromising cooperation with a patient, which is by design longterm. The procedure is characterized by a relatively easy, for an experienced bariatric surgeon, technique, and short time of surgery and postoperative hospital stay, which are connected with small expenditure. However, the procedure is not free of complications. In the literature, there are many descriptions of immediate complications such as diaphragm, stomach, spleen and liver damage and bleeding, and bleeding from trocar sites. Also late complications such as band slippage, band migration into the gastric lumen, band or site marginal inflammation, pouch dilatation, oesophagus dilatation and inflammation, marginal ulcer, stomach rotation, band leakage, leakiness between the band and connecting tubing, or tubing and an access port, vomiting and heartburn, and also lack of weight loss are described [4, 6-16].

\section{Aim}

The aim of this study was to present complications after LAGB in our own material.

\section{Material and methods}

From 2005 to 2010, in the $1^{\text {st }}$ Department of General and Endocrine Surgery, 110 patients were treated by adjustable gastric banding due to morbid obesity. They constituted $1 / 3$ of all bariatric patients (Table I). All procedures were performed laparoscopically. A Soft Gastric Band was placed in 50 patients and a Swedish Adjustable Gastric Band (SAGB) was placed in 60. There were 76 women (69.1\%) and 34 men (30.9\%) in the series. The average age of female patients was $37.7 \pm 13.80$ years old, and of male patients it was $38.9 \pm 11.50$ years old. The average body mass was $128.5 \pm 24.35 \mathrm{~kg}$ for women and 125.4 $\pm 23.60 \mathrm{~kg}$ for men. The average BMI for women was $44.08 \pm 3.03 \mathrm{~kg} / \mathrm{m}^{2}$ and for men $43.66 \pm 2.90 \mathrm{~kg} / \mathrm{m}^{2}$. The average waist circumference was $113.5 \pm 12.75 \mathrm{~cm}$ in women and for men it was $124.40 \pm 14.8 \mathrm{~cm}$ (Table II). Body mass index over 40 or $35 \mathrm{~kg} / \mathrm{m}^{2}$ with concurrent complications or diseases accompanying obesity were indications for bariatric surgery. A series of tests

Table I. Quantitative distribution of bariatric surgeries in Ist Department of General and Endocrinological Surgery, Medical University of Bialystok from 2005 to 2010

\begin{tabular}{|lcc|}
\hline Procedure & \multicolumn{2}{c|}{ Number of patients $(N=314)$} \\
\cline { 2 - 3 } & $n$ & $\%$ \\
\hline LSG & 135 & 43.00 \\
\hline LAGB & 110 & 35.03 \\
\hline RYGB & 61 & 19.42 \\
\hline Mini RYGB & 6 & 1.92 \\
\hline BPD & 2 & 0.63 \\
\hline
\end{tabular}

LSG - laparoscopic sleeve gastrectomy, LAGB - laparoscopic adjustable gastric banding, RYGB - Roux-en-Y gastric bypass, BPD - biliopancreatic division

Table II. Characteristics of patients undergoing LAGB due to morbid obesity

\begin{tabular}{|lcc|}
\hline Parameter & Male & Female \\
\hline Number of patients $(n=110)$ & $n=34,30.90 \%$ & $n=76,69.10 \%$ \\
\hline Median age [years] & $38.90 \pm 11.5$ & $37.70 \pm 13.80$ \\
\hline Median body mass [kg] & $125.4 \pm 23.60$ & $128.5 \pm 24.35$ \\
\hline Median BMI [kg/m²] & $43.66 \pm 2.90$ & $44.08 \pm 3.03$ \\
\hline Median circumference $[\mathrm{cm}]$ & $124.40 \pm 14.80$ & $113.5 \pm 12.75$ \\
\hline
\end{tabular}


was performed in conjunction with the procedure. It included full morphological, biochemical and enzymatic analysis (ALT, AST) with assessment of lipid (total cholesterol, triglycerides, HDL, LDL), carbohydrate and hormonal economy (TSH, fT3, fT4). Moreover, all the patients had USG of the abdominal cavity and gastroscopy performed. Each time behaviour and dietary habits were analysed. Additionally, gynaecological consultation was required in the case of female patients. The remaining tests were recommended with regard to concurrent diseases. The procedures were performed laparoscopically. The adjustable band was placed at the cardiac region of the stomach. It separated the stomach into two areas: a 20-30 ml upper part and the remaining, lower part. After insertion of the Veress needle and establishing pneumoperitoneum $(15-18 \mathrm{~mm} \mathrm{Hg}), 5$ trocars were inserted. The first $10 \mathrm{~mm}$ optic trocar was placed above the navel at a $10 \mathrm{~cm}$ distance between the navel and the left costal arch. The second $10 \mathrm{~mm}$ trocar for the retractor was placed in the median line of the body, just below the xiphisternum. The next trocar, with a diameter of $5 \mathrm{~mm}$, which was used to place a dissector, a coagulation device or a harmonic knife, was placed below the left costal arch in the midclavicular line. Then the trocar site was widened in order to insert the band into the peritoneal cavity and place the band port in the subcutaneous tissue towards the end of the procedure. The fourth trocar, for the grasper and goldfinger, was inserted below the right costal arch in the midclavicular line. The last, sometimes used, $10 \mathrm{~mm}$ trocar for the Babcock grasper was placed in the anterior axillary line at the level of the first trocar. After all the trocars had been placed, the table was lowered to the $30 \%$ semiFowler's position. A window in the gastrophrenic ligament, above the angle of His, was made with the harmonic knife or coagulation device. Similarly, the hepatogastric ligament was incised and the right crus of diaphragm was made visible. A canal behind the posterior stomach wall was created in order to pull the band with a goldfinger device or blunt grasper. After closing the band with a tension device, 2 fixing sutures were placed in the anterior abdominal wall. The tube connecting the band with the port was passed out and the port was attached to the left costal arch. In the postoperative period all the patients received antibiotic and anticoagulant therapy in the form of lower limb compression therapy and low-molecular-weight heparin, and after the pro- cedure detailed dietary recommendations. For the first 2 weeks patients followed a liquid diet and then a low-fat and low-carbohydrate diet under the control of a dietary clinic. The circumference of the band enabled adjustment through a subcutaneous port. The first adjustment was performed at least 6 weeks after the surgery, and the following ones were performed minimally at 3 month intervals. During the adjustment, $3 \mathrm{ml}$ of saline maximum was used. After the first 2 adjustments, the test of liquid and food intake took place, and after the next $2 \mathrm{X}$-ray examination during which the passage of the contrast through a constricted stomach was assessed.

\section{Results}

In the analysed clinical material, which consisted of 110 patients after laparoscopic adjustable band placement, in $36 \%$ of them at least 1 complication occurred. The observed complications were divided into early, those which appeared less than 1 month after the procedure, and late. Among early complications, intraoperative injury to the left diaphragm occurred in 2 cases (1.8\%) which resulted in tension pneumothorax. In the $1^{\text {st }}$ case pleural drainage was performed on an ad hoc basis, while in the $2^{\text {nd }}$ the pneumothorax was treated conservatively due to its small size. However, it became complicated with left lung pneumonia and empyema, which required thoracotomy end evacuation. The procedure was performed 2 weeks after the band placement. In 1 patient $(0.9 \%)$ stomach perforation occurred on the $4^{\text {th }}$ postoperative day. It resulted in diffuse peritonitis with septic shock (Figure 1). The band was removed laparoscopically, the perforation was closed, and drainage of the peritoneal cavity performed. The probe was introduced into the stomach. It was left there for a few days. Two cases (1.8\%) of lower limbs thrombophlebitis were observed, which occurred despite standard anticoagulant prophylaxis on the $7^{\text {th }}$ and $10^{\text {th }}$ postoperative day (Figure 2). Irritating vomiting was reported by 8 patients (7.27\%). The symptoms appeared shortly after band adjustment. Conservative treatment was employed or the band tightness was decreased. Among late complications, oesophagitis (10 patients, 9.09\%) and heartburn (10 patients, 9.09\%) were the most frequent. Standard conservative treatment was used in both cases. The symptoms occurred 11-24 months after the band placement. Band slippage occurred in $7 \mathrm{ca}$ - 


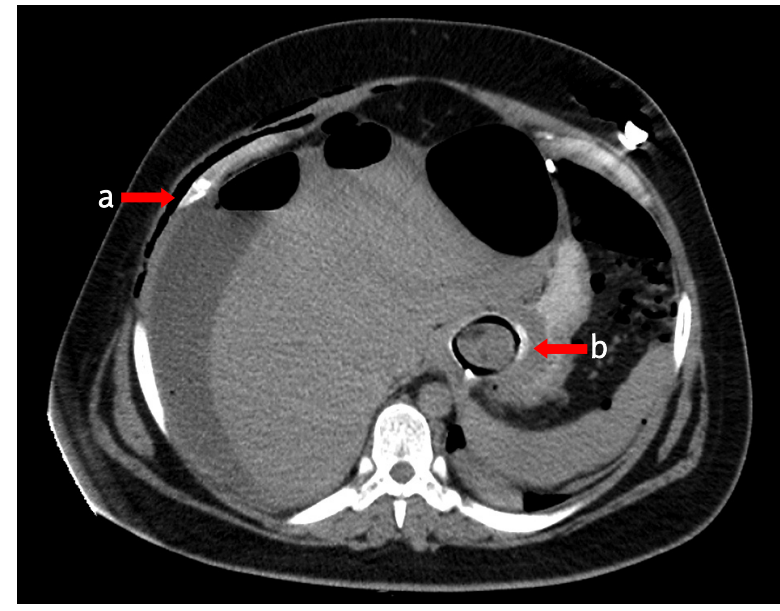

Figure 1. Abdominal $\mathrm{CT}$ of diffuse peritonitis $a$-liquid, $b$-band

ses (6.36\%) 8-36 months after the procedure, which caused symptoms of severe gastrointestinal tract obstruction such as vomiting, stomach ache, or electrolyte imbalances (Figure 3). The symptoms of different intensity accompanying band slippage lasted

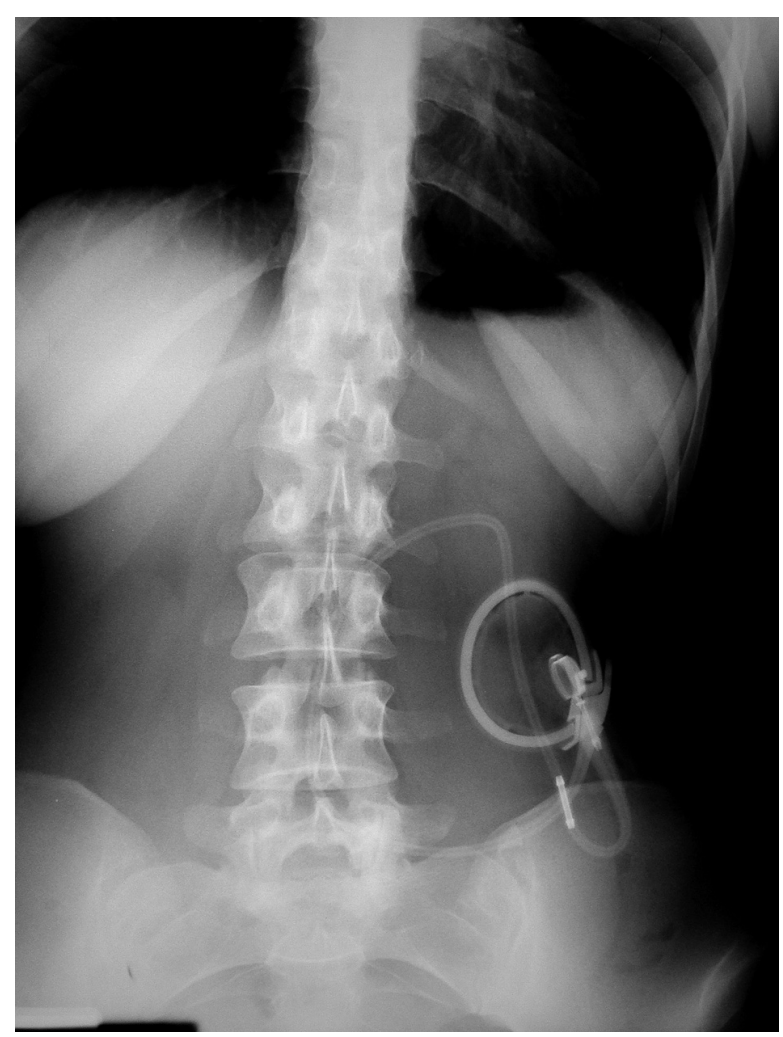

Figure 3. Band slippage to the body of the stomach on RTG

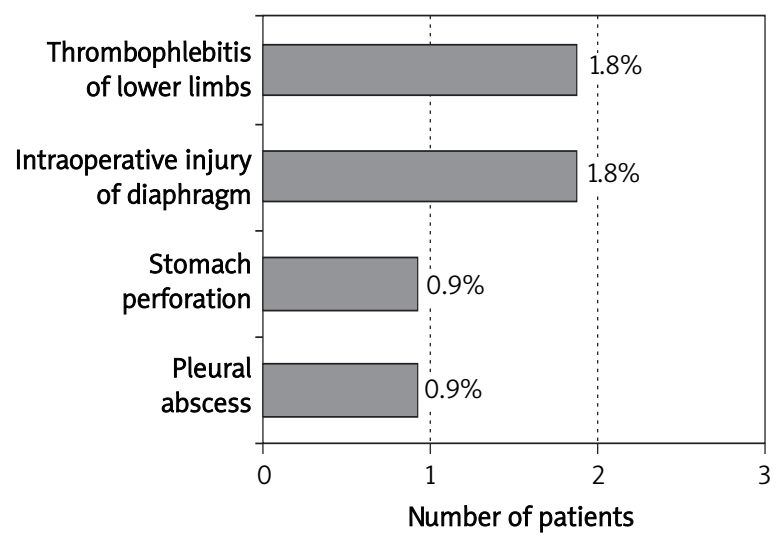

Figure 2. Early complications after LAGB in own material

for a period of 2 weeks to 3 months. They necessitated its laparoscopic removal. Infection and suppuration of the band's marginal area was observed in 5 cases $(4.54 \%)$ over the period of $11-36$ months following the procedure (Figure 4). In 2 cases suppuration coexisted with band slippage. The band was removed together with its port. In the remaining 3 cases temporary port removal took place. Over the period of 18, 25, 36 and 42 months after the procedure, 4 cases $(3.63 \%)$ of band migration to the stomach lumen were observed (Figure 5, Table III). In 2 patients the band was removed endoscopically. In both cases the stomach probe was left for 7 days, and

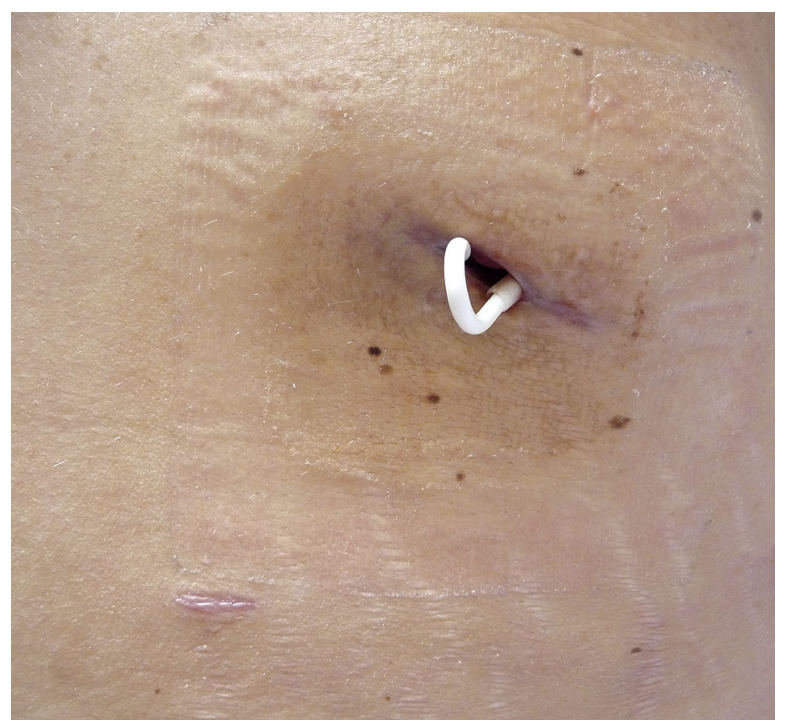

Figure 4. Suppuration of the band's marginal area 


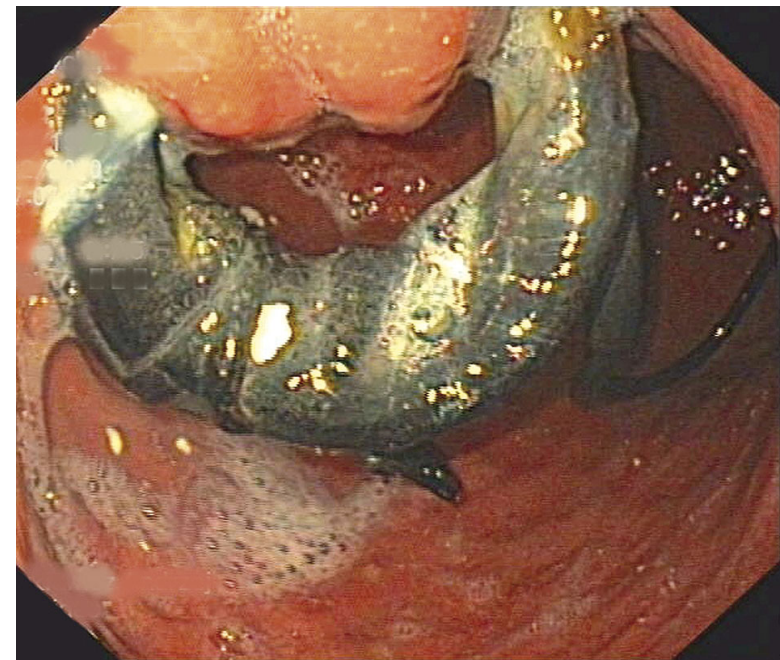

Figure 5. Migration of $3 / 4$ of the band to stomach lumen removed laparoscopically

next the radiological inspection of proper sealing was performed. In 1 patient the band was removed by laparotomy, as it migrated as far as the small bowel, around $50 \mathrm{~cm}$ behind the ligament of Treitz, causing local necrosis of the bowel. The bowel was partially resected (Figure 6). In the last case the migrating band was removed by laparoscopy, and then conservative treatment was employed. Drainage of the peritoneal cavity and stomach probe were maintained for 14 days and the stomach wall at the migration area healed (Figures 7-8) [6, 7]. In 3 (2.72\%) ulceration of the marginal area took place. It was

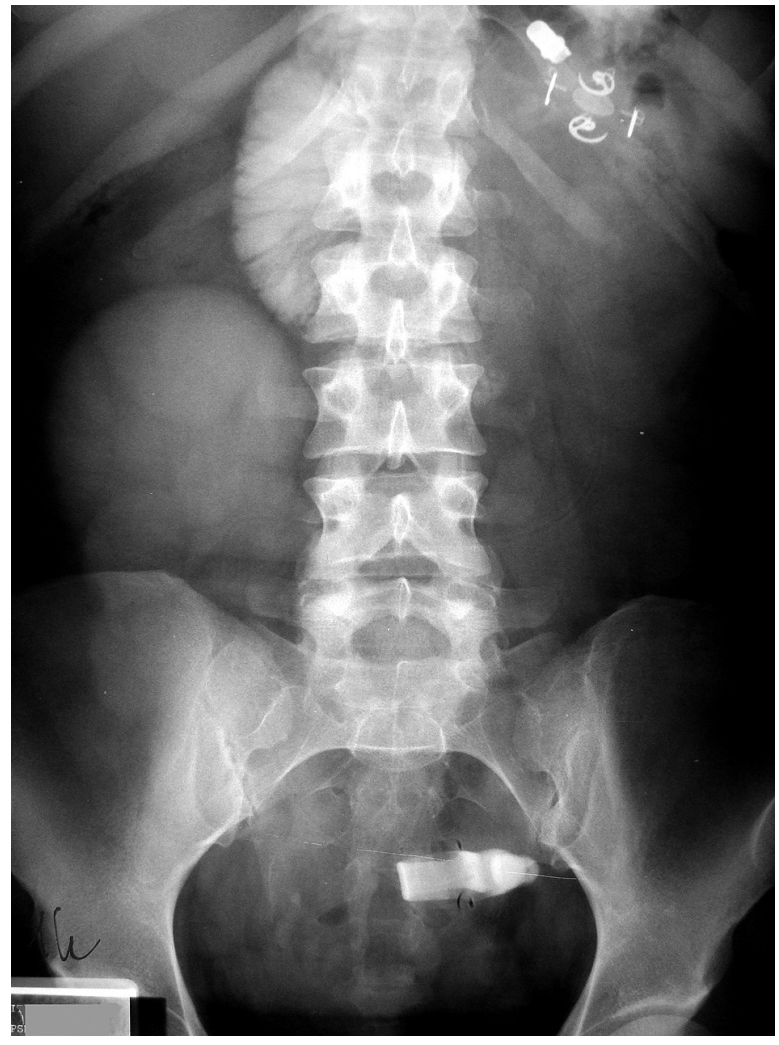

Figure 6. Migration of the band to the lumen of gastrostintestinal tract localized in the small intestine on RTG

managed conservatively for a few weeks. Such treatment turned out to be successful in 1 case, and in the remaining 2 band removal was necessary. In

Table III. Post-LAGB complications in selected European and Polish centres

\begin{tabular}{|lcccc|}
\hline Complication & $\begin{array}{c}\text { Austria, } \\
\text { Lanthalter et al. }\end{array}$ & $\begin{array}{c}\text { Switzerland, } \\
\text { Suter et al. }\end{array}$ & $\begin{array}{c}\text { Wejherowo, } \\
\text { Michalik et al. }\end{array}$ & $\begin{array}{c}\text { Bialystok, } \\
\text { Razak Hady et al. }\end{array}$ \\
\hline Total [\%] & 53.00 & 33.00 & - & 36.00 \\
\hline Problems with port or drain [\%] & 21.6 & 8.00 & 1.00 & - \\
\hline Band migration [\%] & 20.5 & - & - & - \\
\hline Band leak [\%] & 20.5 & 1.00 & - & $2.72 / 9.09$ \\
\hline Oesophageal dilatation/oesophagitis [\%] & 5.8 & 3.00 & 2.00 & $2.72 / 6.36$ \\
\hline Pouch dilatation/band slippage [\%] & 18.9 & 6.3 & - & 7.27 \\
\hline Vomiting/reflux [\%] & 4.2 & 6.9 & 2.00 & 4.54 \\
\hline Port marginal infection [\%] & 2.6 & 1.2 & 1.00 & 0.90 \\
\hline Stomach perforation [\%] & - & 9.5 & 10.5 & - \\
\hline Lack of weight loss [\%] & - & & -1.80 \\
\hline
\end{tabular}




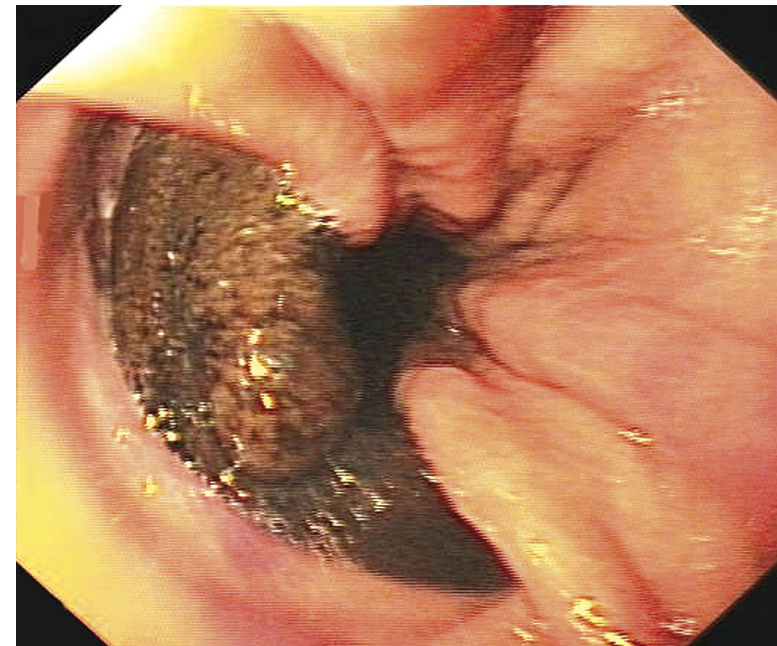

Figure 7. Migration of $1 / 4$ of the band to the stomach lumen removed laparoscopically

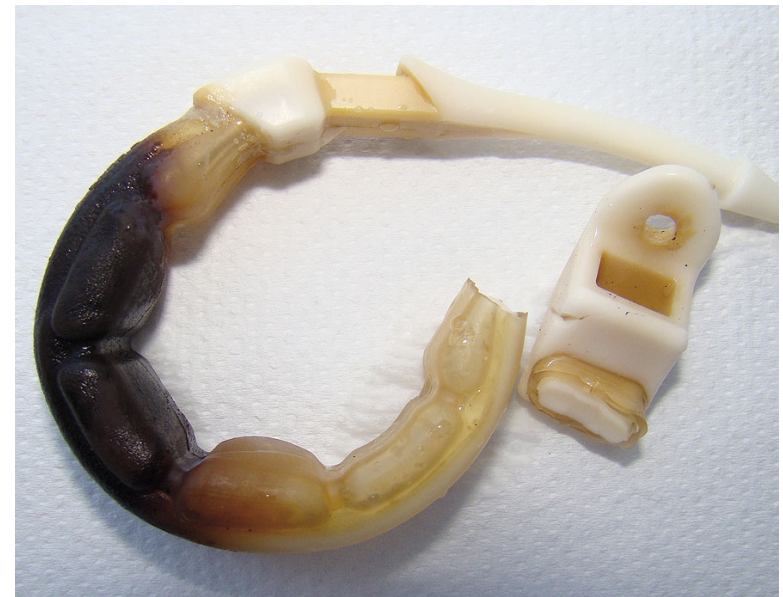

Figure 8. The band from Figure 7 after removal

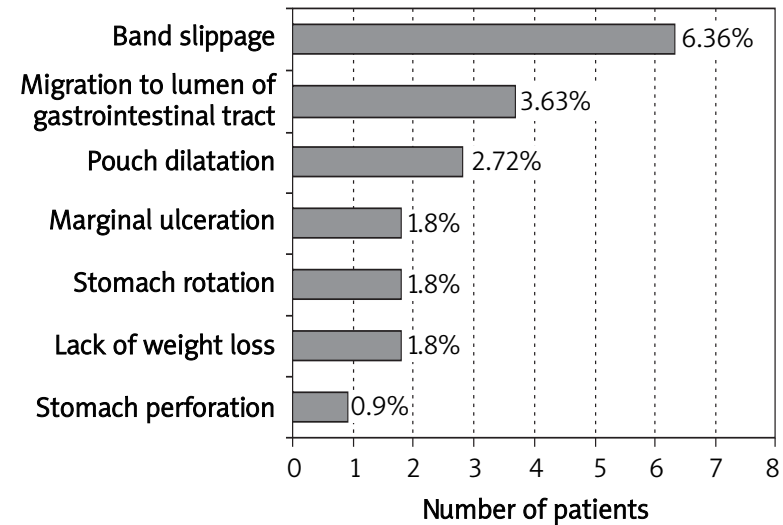

Figure 9. Causes of band slippage in own material $(n=21,19.09 \%)$
$3(2.72 \%)$ oesophageal dilatation was observed and in another $3(2.72 \%)$ gastric pouch dilatation caused by excessive food intake took place. No restrictive effect of the pouch resulted in band removal (Figure 9). In 2 (1.8\%) of those operated on, rotation of the stomach occurred. In both cases it was caused by adhesions between the band and in 1 case with the spleen, in the other with the left lobe of the liver. Both patients complained about repeated nausea and vomiting (Figure 10). Additionally, electrolyte imbalance, which was corrected, was observed. Two patients (1.8\%) reported unsatisfactory weight loss (Figure 11). In our material we had 21 (19.09\%) bands removed due to different early and late complications (Table IV). Only 8 patients were re-operated within different, minimum 3-month periods after band removal. In 2 cases gastric bypass and in the remaining 6 gastric sleeve resection was performed.

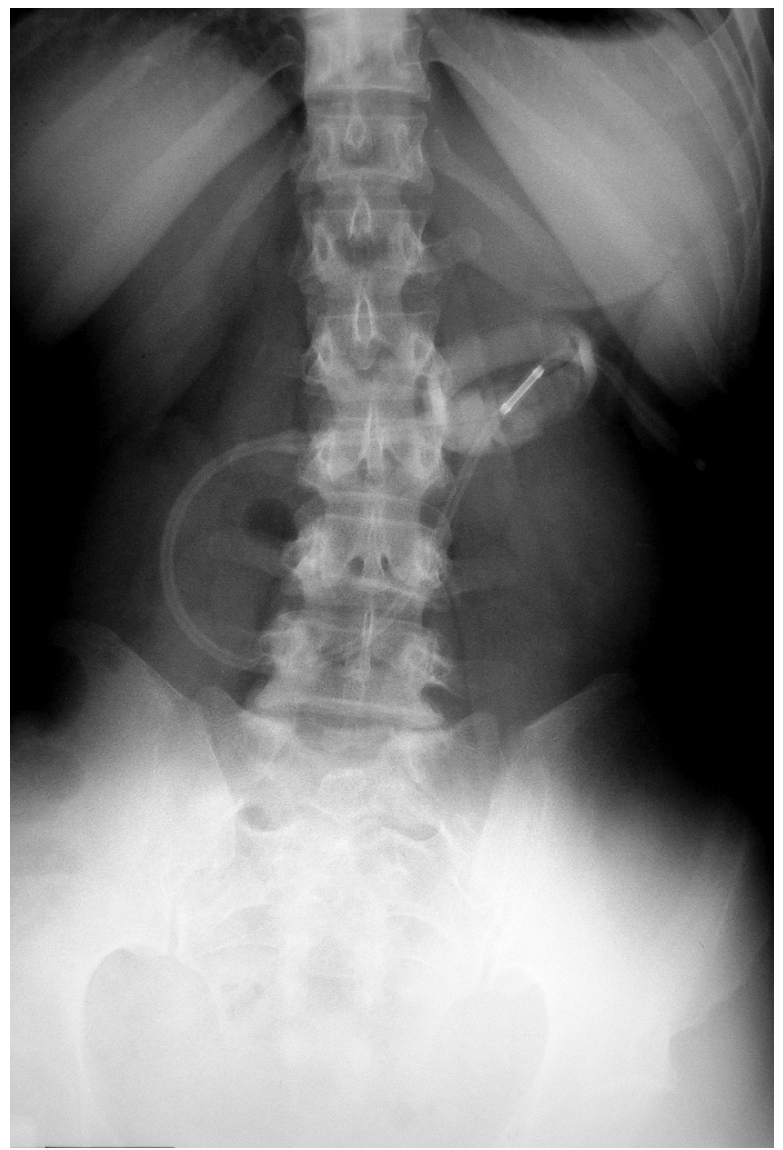

Figure 10. Abdominal RTG with rotated band 


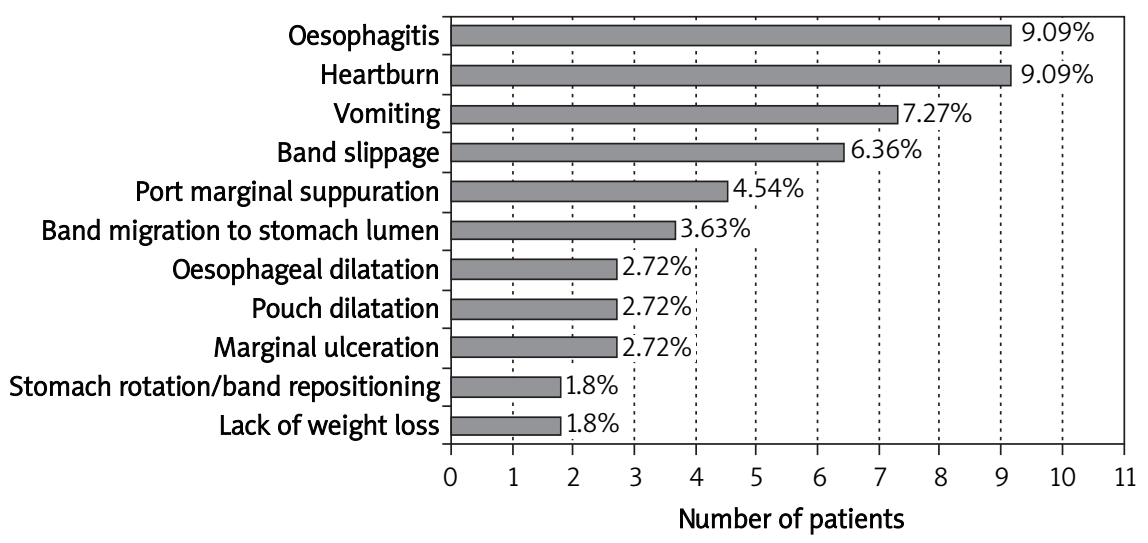

Figure 11. Late complications after band placement in own material

Table IV. Causes of band removal in selected bariatric centres

\begin{tabular}{|lccc|}
\hline Cause & $\begin{array}{c}\text { Austria, } \\
\text { Lanthalter } \text { et al. }\end{array}$ & $\begin{array}{c}\text { Virginia, } \\
\text { De Maria et al. }\end{array}$ & $\begin{array}{c}\text { Bialystok, } \\
\text { Razak Hady et al. }\end{array}$ \\
\hline Total number of removed bands [\%] & 29.5 & 50 & 19.09 \\
\hline Pouch dilatation [\%] & 21.5 & - & 2.72 \\
\hline Band migration to the lumen of the stomach [\%] & 20.5 & - & 3.63 \\
\hline Band or port marginal site infection [\%] & 5.8 & 11.1 & - \\
\hline Band leak [\%] & 20.5 & 11.1 & - \\
\hline Imbalance of the oesophagus [\%] & 5.8 & - & 1.3 \\
\hline Band slippage [\%] & - & 33 & 1.8 \\
\hline Lack of weight loss [\%] & - & - & 0.9 \\
\hline Stomach perforation [\%] & - & - & 1.8 \\
\hline Stomach rotation [\%] & & - & - \\
\hline
\end{tabular}

\section{Discussion}

Despite LAGB being one of the most frequently employed bariatric procedures, it poses a risk of relatively many, sometimes life-threatening complications. The increasing number of LAGB procedures performed all over the world necessitates clinical analysis of its safety and effectiveness. After the initial enthusiasm, flaws and dangers of the method are often emphasized. In some European countries, contrary to the USA, a decrease in the number of LAGB performed is observed, mostly because of coexisting inconvenience and complications. It seems that every bariatric LAGB should be performed in reference centres having at their disposal properly prepared and experi- enced medical staff. Postoperative complications of bariatric procedures are among the most difficult in abdominal surgery. They are not easy to diagnose, and extremely difficult to treat conservatively and surgically. Laparoscopic management of bariatric complications requires a high level of surgical skills. PostLAGB complications are incredibly diverse. Some of them are connected with the use of bands made of artificial materials, which generates varied and individual body, including peritoneal cavity, reactions. It is possible that such a reaction might have caused adhesions and stomach rotation in patients from our series. In the available international literature it can be found that early intraoperative complications such as iatrogenic damage of parenchymal organs, diaphragm 
and stomach remain a serious, life-threatening complication, in many cases missed intraoperatively [6, 7, 17]. Intraoperative diaphragm injury (1.8\%), stomach perforation $(0.9 \%)$, pleural abscess $(0.9 \%)$ and thrombophlebitis (1.8\%) were observed in our own material (Figure 2). In the European bariatric centres post-LAGB complications are analysed. Forestieri et al. (Naples, Italy) report suppurative inflammation of the port area reaching up to $58 \%$ as the most common complication in their material. However, they believe band migration is the most serious one. It often necessitates its removal, which happens in $11 \%$ of cases. In our material band migration was observed 4 times, which constituted $3.63 \%$ of cases. Half the patients were treated endoscopically. Endoscopic removal of the migrating band appears to be the most optimal and the least invasive method. It allows one to avoid surgery and minimizes the costs of treatment [9]. Marginal ulceration, alteration of the position and angle of deviation, and uneven pressure on the stomach wall may be the most common causes of band migration [18]. In the Austrian centre band migration was observed in $20.5 \%$ of cases. According to their clinical data at least 1 complication occurred in around $53 \%$ of patients. The complications most commonly observed by them were lack of integrity between a port and catheter (21.6\%), band migration (20.5\%), leak in a band (20.5\%), and pouch dilatation (18.9\%) [7]. All the above-mentioned complications occurred in our material much less frequently (Table III); however, the disparity in the number of patients operated on should be taken into account in this analysis. Suter et al. (Switzerland) report that in their material in $33.1 \%$ of patients at least 1 postoperative complication occurred and $29.6 \%$ required surgical revision. Lack of weight loss (10.5\%), band erosion $(9.5 \%)$ and leak in the port or catheter's marginal area $(7.6 \%)$ are the most frequently observed complications. $7.6 \%$ of bands were removed [8]. We observed fewer complications of such kind in our own material. Band slippage causes are not entirely explained. The band is intraoperatively fixed with 1 or 2 sutures, but peristaltic movement, increased food intake in the upper reservoir and its gradual dilatation probably cause the band to slip as far as the body of the stomach and sometimes even to the pylorus. According to the literature this complication is observed in 1-22\% of patients [19-24]; in our material it occurred only in $2.72 \%$ of cases. Oesophagitis was observed in $11.81 \%$ of patients in our material.
According to German research including patients after LAGB who underwent 30 months of observation, the complication took place in around $30 \%$ of those operated on, while incorrect $\mathrm{PH}$ was noted in $43.8 \%$ of patients [25]. The occurrence rate of band erosion was estimated at less than $1 \%$ in the literature $[13,15,17]$. We did not observe this complication in our own material. When post-LAGB life- or healththreatening complications occur, we face the necessity to remove the band. Most frequently it happens due to band migration to the gastrointestinal tract, its migration combined with severe obstruction of the tract, stomach perforation, ulceration which cannot be treated conservatively and upper pouch dilatation. In our material we noted 21 cases (19.09\%) of removed bands. The most common causes were band slippage (6.36\%), migration to the lumen of the stomach (3.63\%) and pouch dilatation (2.72\%). We compared our results with those of other international centres (Table IV). The presented data are comparable to international data. We observed oesophageal dilatation and oesophagitis more often. The majority of complications were observed in the first years of LAGB usage.

\section{Conclusions}

Despite relatively simple surgical technique, LAGB is connected with quite a large number of intraoperative, early and late complications, both mild and severe, even life threatening. Obese patients are more vulnerable to perioperative risk and increased incidence of complications, not only due to their adiposity, but also because of concurrent diseases. The LAGB procedures should be performed in reference centers dealing with bariatric surgery and with suitable experience. Complications incidence decreases with time and increasing skills and experience of the surgical team.

\section{References}

1. Abir F, Bell R. Assessment and management of the obese patient. Crit Care Med 2004; 32 (4 Suppl): S87-91.

2. Stanowski E, Paśnik K. Bariatric surgery - the current state of knowledge. Videosurgery Miniinv 2008; 3: 71-86.

3. Paśnik K, Wyleżoł M, Stanowski E. Metody chirurgicznego leczenia otyłości. Postępy Nauk Medycznych 2009; XXII, nr 7.

4. Szydłowski K, Frask A, Michalik M, et al. Complications after surgical treatment of obesity based on own material. Videosurgery Miniinv 2008; 3: 45-52 
5. Cunneen S. Review of meta-analytic comparisons of bariatric surgery with a focus on laparoscopic adjustable gastric banding. Surg Obes Relat Dis 2008; 4 (3 Suppl): S47-55.

6. Forestieri P, Pilone V, Tramontano S, et al. Laparoscopic gastric band migration: role of environmental factors in the experience of a single team in three operating rooms. Obes Surg 2010; 20: 1333-9.

7. Lanthaler M, Aigner F, Kinzl J, et al. Long-term results and complications following adjustable gastric banding. Obes Surg 2010; 20: 1078-85.

8. Suter M, Calmes JM, Paroz A, et al. A 10-year experience with laparoscopic gastric banding for morbid obesity: high long-term complication and failure results. Obes Surg 2006; 16: 829-35.

9. Chen Yi Mei SG, Tam W, Nind G, Singh R. Endoscopic removal of migrating silastic band after vertical banding gastroplasty. Endoscopy 2010; 42 Suppl 2: E253.

10. Favretti F, Cadiere GB, Segato G, et al. Laparoscopic banding: selection and technique in 830 patients. Obes Surg 2002; 12: 385-90.

11. Chevallier J, Zinzindohoue F, Douard R, et al. Complications after laparoscopic gastric banding for morbid obesity: experience with 1000 patients over 7 years. Obes Surg 2004; 14: 407-14.

12. Eid I, Birch DW, Sharma AM, et al. Complications associated with adjustable gastric banding for morbid obesity: a surgeon's guide. Can J Surg 2011; 54: 61-6.

13. O'Brien P, Dixon J. Weight loss and early and late complications - the international experience. Am J Surg 2002; 184: 42S-5S.

14. Martikainen T, Pirinen E, Alhava E, et al. Long-term results, late complications and quality of life in a series of adjustable gastric banding. Obes Surg 2004; 14: 648-54.

15. Niville E, Dams A, Vlasselaers J. Lap-band erosion: incidence and treatment. Obes Surg 2001; 11: 744-7.

16. Hady Razak H, Dadan J, Zbucki R, et al. Complications after laparoscopic adjustable gastric banding (LAGB) operations. Obes Surg 2010; 20, P-057.

17. Msika S. Surgery for morbid obesity: 2. Complications. Results of a technologic evaluation by the ANAES. J Chir (Paris) 2003; 140: 4-21.

18. Wolff S. Intragastric penetration of gastric band - a severe complication after gastric banding? Zentralbl Chir 2002; 127: 1086-9.

19. Weiner R, Blanco-Engert R, Weiner S, et al. Outcome after laparoscopic adjustable gastric banding-8 years experience. Obes Surg 2003; 13: 427-34.

20. O'Brien PE, Dixon JB, Brown W, et al. The laparoscopic adjustable gastric band: a prospective study of medium-term effects on weight, health and quality of life. Obes Surg 2002; 12: 652-60.

21. Suter M. Laparoscopic band repositioning for pouch dilatation/slippage after gastric banding: disappointing results. Obes Surg 2001; 11: 507-12.

22. Fielding GA, Ren CJ. Laparoscopic adjustable gastric band. Surg Clin North Am 2005; 85: 129-40.

23. Sarker S, Herold K, Creech S, et al. Early and late complications following adjustable gastric banding. Am Surg 2004; 70: 146-9.
24. Tran D, Rhoden DH, Cacchione RN, et al. Techniques for repair of gastric prolapse after laparoscopic gastric banding. J Laparoendosc Adv Surg Tech A 2004; 14: 117-20.

25. Gutschow CA, Collet P, Prenzel K, et al. Long-term results and gastroesophageal reflux in a series of laparoscopic adjustable gastric banding. J Gastrointest Surg 2005; 9: 941-8. 